\title{
GCU
}

Glasgow Caledonian

University

University for the Common Good

\section{Assessment of predicted versus measured thermal comfort and optimal comfort ranges in the outdoor environment in the temperate climate of Glasgow, UK}

Oertel, Annika; Emmanuel, Rohinton; Drach, Patricia

Published in:

Building Services Engineering Research and Technology

DOI:

$10.1177 / 0143624414564444$

Publication date:

2015

Document Version

Author accepted manuscript

Link to publication in ResearchOnline

Citation for published version (Harvard):

Oertel, A, Emmanuel, R \& Drach, P 2015, 'Assessment of predicted versus measured thermal comfort and optimal comfort ranges in the outdoor environment in the temperate climate of Glasgow, UK', Building Services Engineering Research and Technology, vol. 36, no. 4, pp. 482-499 . https://doi.org/10.1177/0143624414564444

\section{General rights}

Copyright and moral rights for the publications made accessible in the public portal are retained by the authors and/or other copyright owners and it is a condition of accessing publications that users recognise and abide by the legal requirements associated with these rights.

Take down policy

If you believe that this document breaches copyright please view our takedown policy at https://edshare.gcu.ac.uk/id/eprint/5179 for details of how to contact us. 


\title{
Assessment of predicted versus measured thermal comfort and optimal comfort ranges in the outdoor environment in the temperate climate of Glasgow, UK
}

\author{
Annika Oertel, Rohinton Emmanuel ${ }^{*}$, Patricia Drach \\ *corresponding Author: Rohinton.Emmanuel@gcu.ac.uk
}

\begin{abstract}
In a warming world the risk of overheating is significant in temperate climate areas such as Glasgow, UK where adaptation to overheating is low. An easy-to-use thermal comfort evaluation is therefore a necessary first step towards developing effective coping mechanisms. In this study we explore the effectiveness of Predicted Mean Vote (PMV), Predicted Percentage of Dissatisfied (PPD) and Physiologically Equivalent Temperature (PET), together with air temperature in mimicking actual thermal sensation votes of street users obtained in 2011 in Glasgow City Centre. The PMV/PPD indices developed for controlled indoors show a surprising similarity to actual thermal sensation votes derived from outdoor surveys, than the PET developed specifically for the outdoors. The method of calculation of mean radiant temperature $\left(\mathrm{T}_{\mathrm{mrt}}\right)$ is key to improved performance of PET, with fish-eye lens photographs improving its performance. The results also show air temperature $\left(\mathrm{T}_{\mathrm{a}}\right)$ alone has nearly equal predictive power of the actual thermal sensation. A preliminary comfort range for Glasgow is also derived and its limitations are explored.
\end{abstract}

Keywords: Environmental comfort; Comfort ranges; Thermal comfort; PMV; PET

\section{Practical applications}

The strong relation between thermal sensation votes and $T_{a}$ enables future thermal comfort studies to predict the thermal comfort using easy-to-access $\mathrm{T}_{\mathrm{a}}$ only. A current thermal comfort study in Glasgow aiming at developing a link between urban morphology and $\mathrm{T}_{\mathrm{a}}$ is already using this strong relation to predict outdoor thermal comfort in the city centre. This helps to establish a correlation between these three factors.

\section{Bibliographic information:}

Oertel A, Emmanuel R, Drach. P. 2014. Assessment of predicted versus measured thermal comfort and optimal comfort ranges in the outdoor environment in the temperate climate of Glasgow, UK. Building Services Engineering Research and Technology, DOI: $10.1177 / 0143624414564444$ http://bse.sagepub.com/content/early/2014/12/18/0143624414564444.abstract 


\section{Introduction and background}

The determination of the thermal comfort and thermal stress in outdoor environments, both in an effective and a practical way, is known to be one of the most important applications in human biometeorology ${ }^{1}$. Thermal stress negatively influences health in different ways. Apart from the reduction of general wellbeing, heat stress also reduces health and productive efficiency. ${ }^{2,3}$ Moreover heat stress might be associated with the decrease in use of outdoor space $^{4}$. Besides, as studies on the impact of heat waves show, a link between morbidity/mortality and heat stress exists ${ }^{1,4}$. This was evident in the 2003 heat wave in Central Europe that led to 14,800 additional deaths due to heat stress. ${ }^{4}$ Given the lack of adaptation to hot conditions in temperate climates such risks exists even at relatively lower temperatures. For example, the threshold temperatures beyond which heat-related mortality rises significantly is $>32^{\circ} \mathrm{C}$ in the equatorial regions, but cities such as London and Stockholm exhibit much lower thresholds $\left(21-23^{\circ} \mathrm{C}\right)^{5}$.

Cities form a complex structure and modify atmospheric conditions in the urban canopy layer. One of the best known phenomena is the urban heat island (UHI) which increases heat stress especially in warm periods. The intensity of the UHI varies according to form, material and density of the urban structure ${ }^{1}$. Three different methods to minimize the influence of severe heat on urban dwellers exist ${ }^{6}$ : implementation of heat warning systems, individual adaptation of citizens by clothing and behaviour and urban planning strategies.

In order to reduce thermal stress pre-emptively, especially in light of overheating risk associated with future climate change exacerbated by the UHI effect ${ }^{7,8}$ biometeorology needs to provide information for adapting urban structures to decrease heat stress ${ }^{1}$. A reliable 
assessment of the thermal comfort of the population in complex urban structures based on actual thermal comfort surveys is a necessary first step in this regard.

A common practice to estimate thermal comfort is to use rational thermal indices, which are based on the human body energy balance and are said to be universally applicable. ${ }^{1}$ However, the adaptive comfort theory ${ }^{9}$ continues to challenge this notion, and posits that comfort is a function of the thermal context and exhibits significant spatial and temporal variations. Nevertheless, several different thermal indices continue to be used for the assessment of the thermal comfort conditions. The present work focuses on Fanger's Predicted Mean Vote (PMV) and the Predicted Percentage of Dissatisfied (PPD) according to ISO $7730^{10}$ as well as the Physiologically Equivalent Temperature (PET) ${ }^{11}$. PMV/PPD indices were originally developed for indoor environments. The PMV predicts the mean value of the votes of a large group of persons based on the human body heat balance and is arranged in a seven-point thermal sensation scale (hot, warm, slightly warm, neutral, slightly cool, cool and cold). The PPD establishes a quantitative prediction of the percentage of thermally dissatisfied people, representing those who voted hot, warm, cool or cold in scale of PMV thermal sensation. The PMV value is taken into account to calculate the PPD ${ }^{10}$. PET index ${ }^{11}$ on the other hand, is expressed in ${ }^{\circ} \mathrm{C}$ and is defined as the equivalent temperature to the air temperature in which, for a given situation, the thermal balance of a person remains the same, with the same core and skin temperatures as in the original situation.

The calculations of these indices are complex, requiring several relevant meteorological parameters that influence the heat balance: air temperature $\left(T_{a}\right)$, relative humidity $(R H)$, wind velocity $\left(\mathrm{V}_{\text {wind }}\right)$ and mean radiant temperature $\left(\mathrm{T}_{\mathrm{mrt}}\right)$. While $\mathrm{T}_{\mathrm{a}}$ and $\mathrm{RH}$ are commonly measured, $\mathrm{T}_{\text {mrt }}$ and $\mathrm{V}_{\text {wind }}$ are infrequently measured (with significant exceptions ${ }^{13,14,15}$ ) and 
secondary data, especially site specific urban data, is hard to obtain ${ }^{11,12}$. The modelling of necessary input parameters for calculating thermal indices is an easier way to generate necessary thermal comfort input data ${ }^{12}$. Other more complex and costly methods include measurement campaigns ${ }^{16}$ which, nevertheless, supply more precise data ${ }^{11}$.

Given the acclimatisation of population to local conditions it is imperative that contextually relevant thermal comfort estimations are carried out for each locality. An easy-to-use and low cost method to do so will greatly facilitate rapid estimation of the thermal comfort consequences of urban development options. It will also help identify the likely thermal comfort effects of a changing climate more readily, thus helping planners and designers prepare more robust adaptive options.

This study provides a basis for future thermal comfort studies in temperate climate outdoors based on models and measurement campaigns, by investigating the relationship between (1) the actual thermal sensation of Glaswegian population, derived from an outdoor survey campaign conducted previously in Glasgow City Centre, Glasgow, UK, ${ }^{17,18}$ and $\mathrm{T}_{\mathrm{a}}$ and (2) the relationship between the actual thermal sensation and calculated PMV and (3) the relationship between the actual thermal sensation and modelled PMV. Thus, this study forms a basis for the evaluation of future model outputs and measurement campaigns. Besides, (4) an adjustment of the equation for the calculation of the Predicted Percentage of Dissatisfied (PPD) was conducted.

The accuracy of the PMV/PPD/PET indices depends on the quality of the input data. Towards this end, the paper also explores (5) the effectiveness of the Sky View Factor (SVF, which indicates which part of the sky can be seen from a specific point in the street at the height of pedestrians) on the ability of calculated indices to better mimic actual thermal sensation votes of outdoor users. 


\section{Study area}

Measurements and outdoor comfort surveys were conducted in the city centre of Glasgow, Scotland, UK $\left(55^{\circ} 51^{\prime} \mathrm{N}, 04^{\circ} 12^{\prime} \mathrm{W}\right)$ in a pedestrian area which extended from Sauchiehall Street to Argyle Street and covered parts of Buchanan Street forming the shape of a " $Z$ " as shown in Figure 1. Measurement campaign lasted between March and July 2011 and included 19 outdoor surveys under a wide range of air temperatures, wind conditions and solar angles and heights but mostly under clear-sky conditions. Weather conditions during the measurement period are shown as box plots in Figure 2. Monitored climatic variables (air temperature, relative humidity, wind speed and direction, global horizontal solar radiation and globe temperature) are according to ISO $7726^{19}$. Measurements were taken at five second intervals and averaged over a minute. Each campaign spanned up to three hours (typically from 10am to 1pm). Instrumentation included a Davis Vantage Pro2 weather station equipped with a three cup anemometer (at approximately $1.5 \mathrm{~m}$ height), air temperature and humidity sensors at $1.1 \mathrm{~m}$, silicon pyranometer at $1.4 \mathrm{~m}$. and a globe thermometer. Details of the equipment and their ranges are given in Table 1 and in previous works $^{17}$.

(Figure 1a and $1 \mathrm{~b}$ here)

(Table 1 here)

(Figure 2 here)

The climate of Glasgow is Cfb according to Köppen-Geigers climate classification that states that the climate is temperate and mild due to strong maritime influence. Average maximum $\mathrm{T}_{\mathrm{a}}$ does not exceed $20^{\circ} \mathrm{C}$, with at least five months presenting an average above $10^{\circ} \mathrm{C}$. 
Precipitation is high (annual average $=1300 \mathrm{~mm}$ ) and spread evenly throughout the year ${ }^{20}$. Sunshine is typically low (annual average $=1348 \mathrm{hrs}$ ) with only 3 months (May, June and July) having a monthly average $>150 \mathrm{hrs} /$ month. Wind speed is moderate (annual average speed at $10 \mathrm{~m}$ above ground $=7.7$ knots $[3.96 \mathrm{~m} / \mathrm{s}]$, with below annual average speeds during the summer months $=5.6$ knots $[2.88 \mathrm{~m} / \mathrm{s}]) .^{20}$

Six measurement locations within the pedestrian street area shown in Figure 1b were selected for outdoor comfort surveys and climate measurement. Sky view factor (SVF), street orientation, urban canyon geometry and street type (street junction or squares) were used as criteria for the selection of the measurement locations. The urban characteristics of the monitoring sites are shown in Table 2. A FC-E8 fisheye lens coupled to a digital camera was used for sky view photos and polar photo, black and white mask and the SVF's were derived from RayMan Pro, a public domain software developed by Andreas Matzarakis. ${ }^{21}$

(Table 2 here)

\section{Method}

A three step process was employed by the present study. First, a pedestrian area in Glasgow City Centre as detailed in Section 2 was selected and a field work comprising of micrometeorological measurements and thermal comfort surveys were administered. The second step generated the input files necessary to calculate comfort indices and the Mean Radiant Temperature $\left(\mathrm{T}_{\mathrm{mrt}}\right)$. Finally, the third step carried out comparisons of actual thermal sensation against measured PMV/PPD/PET. 


\subsection{Thermal comfort fieldwork}

Measurement of air temperature $\left(\mathrm{T}_{\mathrm{a}}\right)$, wind speed $\left(\mathrm{V}_{\text {wind }}\right)$, relative humidity $(\mathrm{RH})$ and globe temperature $\left(\mathrm{T}_{\mathrm{g}}\right)$ were conducted at about $1 \mathrm{~m}$ above ground which reflects the centre of the human body, which is necessary to calculate the thermal index according to the human energy balance ${ }^{21}$. Climate measurements employed a Davis Vantage Pro2 weather station and an additional globe thermometer (consisting of a $40 \mathrm{~mm}$ diameter flat grey painted table tennis ball with an enclosed temperature probe [Tinytag-TGP-4500 with external temperature probe], attached to the tripod at $1.1 \mathrm{~m}$ height) which together provided all variables needed for the calculation of $\mathrm{T}_{\mathrm{mrt}}{ }^{17,18}$. Resolution and operational ranges of the equipment are shown in Table 1. Weather conditions during the measurement period are shown as box plots in Figure 2 and details of the solar radiation profiles on survey dates are shown in Figure 3.

Each fieldwork campaign lasted for 3 hours (usually between 10 a.m. and 1 p.m. local time). $\mathrm{T}_{\text {mrt }}$ was calculated according to ISO $7726^{19}$, using Equation 1, for forced convection, taking into account: measured globe temperature $\left(T_{g}\right)$, wind speed $\left(V_{\text {wind }}\right)$, air temperature $\left(T_{a}\right)$, and globe's emissivity $\left(\varepsilon_{\mathrm{g}}\right)$ and diameter (D). In Equation 1 the convective heat loss of the globe depends on size, material, colour and shape of the globe $e^{22}$ as well as on the geographical latitude $^{28}$. Preferably the formula should be calibrated with three-dimensional measurements of short and long-wave radiation fluxes at the site but this would require sophisticated and expensive equipment ${ }^{32}$.

$$
T_{M R T}=\left\{\left(T_{g}+273\right)^{4}+\frac{1.1 \times 10^{8} \times V_{\text {wind }} 0.6}{\varepsilon_{g} \times D^{0.4}} \times\left(T_{g}-T_{a}\right)\right\}^{\frac{1}{4}}-273
$$

(Figure 3)

\subsection{Outdoor comfort surveys}


In addition to the climate measurements a comfort questionnaire was created according to ISO $10551^{23}$ (see Appendix A). The first part of the questionnaire consisted of personal questions including length of residency in Glasgow that accounts for the acclimatisation. Besides, information regarding the time spent outdoors, prior to the interview, was recorded. The second part consisted of symmetrical seven-point with two-pole scale, ranging from -3 cold over 0 neutral to +3 hot, used for assessing the respondent's thermal sensation and thermal preference.

After data cleansing (i.e. removal of surveys from those residing in Glasgow for less than 6 months; pregnant women, construction workers and others likely to have high metabolic rates), the sample consisted of thermal sensation and thermal preference votes under which the largest concentration of data lies in summer due to more stable conditions. Further narrowing of data samples was arranged to accord for the time spent outdoors. A residency

of at least 15 minutes outdoors was used as a criterion as recommended by ANSI/ASHRAE ${ }^{24}$ for indoor thermal comfort assessments, since calculations with IMEM (Instationary Munich Energy-Based Model $)^{25}$ suggest that the thermal adaptation, especially to cold, needs to be taken into account. The sample consisted of $61 \%$ male and $39 \%$ female votes and covered an age range from 12-86 years old. The average number of votes at each measurement site counted $100 \pm 14$. Total sample size after data cleansing consisted of 573 thermal sensation votes.

\section{$\underline{3.3 \text { Assessment of thermal indices }}$}

The thermal indices used in this survey are PMV, PPD and PET. PMV is based on the same seven-point thermal sensation scale as the outdoor comfort survey, thus allowing a comparison of surveyed thermal sensation votes against calculated thermal PMV values ${ }^{10}$. 
PMV was calculated using RayMan Pro ${ }^{12,26}$ software (www.mif.uni-freiburg.de/RayMan) and two different calculations were made using different input parameters. The first calculation included location, date, time, $\mathrm{T}_{\mathrm{a}}, \mathrm{V}_{\mathrm{wind}}, \mathrm{RH}$ and measured $\mathrm{T}_{\mathrm{mrt}}$ as input parameters (This is termed as $\mathrm{PMV}_{\text {measured }}$ ); the second calculation used the same input parameters except for $\mathrm{T}_{\mathrm{mrt}}$. Instead of $\mathrm{T}_{\mathrm{mrt}}$, sky view photos of each thermal comfort survey location and global horizontal solar radiation data, derived from the Glasgow Caledonian University reference station $($ distance to measurement locations $=$ between $0.5-1.1 \mathrm{~km})$ to account for cloud conditions, were used as input variables. In this case, $\mathrm{T}_{\text {mrt, }}$ which is necessary to calculate PMV values, was simulated by RayMan Pro ( $\left.\mathrm{PMV}_{\text {calculated }}\right)$. The motivation was to explore whether a simpler method than using globe thermometers could provide equally robust results. For personal input parameters the default values in RayMan Pro were used for both calculations (male, 35 years, $1.75 \mathrm{~m}, 75 \mathrm{~kg}$ ). Furthermore an estimated metabolic rate of 295 $\mathrm{W}$ was used (walking at $4 \mathrm{~km} / \mathrm{h}$ on level ground, in agreement with the survey assumptions) and a clothing level of 1.55 (based on average values for surveys conducted during Mar-May 2011) for the colder periods and 0.75 (based on average values for Jun-Jul 2011 surveys) for the warmer periods was used.

As PMV only predicts the mean votes of a large group of people, the individual thermal sensation might differ from the calculated mean ${ }^{10}$. Thus, the calculation of the percentage of people who are dissatisfied (PPD) under the current climate conditions, i.e. who feel too cold or too warm, is useful ${ }^{10}$. The thresholds for satisfaction with the thermal comfort were taken to be -0.5 and $+0.5^{21}$. Thus thermal discomfort can be due to heat (thermal sensation votes exceed +0.5 ) and due to cold (thermal sensation votes undershoot -0.5 ). PPD can be derived from PMV / thermal sensation votes as shown in Equation 2 according to ISO $7730^{10}$.

$$
P P D=100-95 \times \exp \left(-0.03353 \times P M V^{4}-0.2179 \times P M V^{2}\right) \quad\left(\text { Equation 2) }{ }^{10}\right.
$$


In order to test the applicability of $\mathrm{T}_{\mathrm{a}}, \mathrm{T}_{\mathrm{mrt}}$ and PMV as predictors of the outdoor thermal sensation of the Glaswegian population, the thermal sensation votes from the outdoor comfort surveys were matched to the measured climate data and to the calculated indices. The applicability of $\mathrm{T}_{\mathrm{a}}, \mathrm{T}_{\text {mrt }}$ and PMV (measured and calculated) to predict the thermal sensation of Glaswegian population was tested using binned data. Bin width and number of bins varied according to the individual variable. The parameters of the binned data used for the computation of the regression equation are shown in Table 3. For each bin, the mean thermal sensation was calculated according to the thermal sensation votes and compared to the $T_{a}$ and PMV data.

(Table 3 here)

\subsection{Statistical Tests}

Statistical tests were conducted using the R Project for Statistical Computing ${ }^{27}$. For the analysis of the relation of predicted versus measured thermal sensation data, simple linear regression equations were calculated and the coefficients of determination were assessed. The correlation between different indices was tested using Pearson's $r$ values. Besides, an analysis of variance (ANOVA) was conducted to test which variable $\left(T_{a}, T_{\text {mrt }}, V_{\text {wind }}\right.$, or $\left.R H\right)$ explains most of the variance in the thermal sensation data and is thus most suitable to predict thermal sensation votes in Glasgow.

Optimal comfort ranges for Glasgow were derived using the regression equations and a thermal comfort zone from -0.5 to $+0.5^{21}$. For the calculation of the actual Percentage of Dissatisfied (PPD) the thermal sensation for each $\mathrm{T}_{\mathrm{a}} / \mathrm{PMV}$ bin was predicted using the regression equations shown in Figures 4 and 5. From the predicted thermal sensation data, the amount of dissatisfied people (i.e. outlying the comfort zone from -0.5 to +0.5 ), was calculated and compared against the computed PPD, which is derived from equation 2, 
setting the predicted thermal sensation data as PMV. The original equation (equation 2) to compute PPD was then optimized to better fit the measured PPD. This was achieved by minimising the sum of squares between the actual PPD and the corresponding computed PPD values.

\section{Results and Discussion}

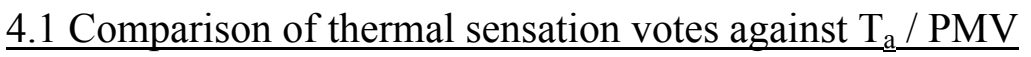

The comparison between the actual thermal sensation votes against $\mathrm{T}_{\mathrm{a}}$ and the predicted thermal sensation (Table 4) for both scenarios, i.e. for calculated and measured PMV, shows weak correlations for raw data but higher correlation for binned data, although both binned and raw data show significant results $(\mathrm{p}<<0.05)$ (Table 5). While higher correlation to binned data is to be expected the very high values in Table 4 indicate that PMV based on measured input data are highly accurate and, in combination with the regression equation, can be used for the prediction of the thermal comfort in outdoor settings of a temperate climate city.

An analysis of variance (ANOVA) shows that $\mathrm{T}_{\mathrm{a}}\left(\mathrm{R}^{2}=86.2 \%\right)$ explains a larger amount of the variance in the thermal sensation votes than $\mathrm{T}_{\mathrm{mrt}}$. Both measured $\mathrm{T}_{\mathrm{mrt}}\left(\mathrm{R}^{2}=59.8 \%\right)$ and calculated $\mathrm{T}_{\mathrm{mrt}}\left(\mathrm{R}^{2}=68.9 \%\right)$ show weaker correlations than $\mathrm{T}_{\mathrm{a}}$.

(Table 4 here)

However, when intending to carry out future thermal comfort studies in Glasgow, e.g. for examination of the influence of urban geometry on the thermal comfort, it is unpractical, expensive and time consuming to measure all necessary input variables at each measurement site and for different hours of a day and climate configurations. 
(Figure 4 here)

Predicted PMV values using fisheye photos and global horizontal solar radiation data as input variables show a good relation, too, as shown in Figure 4. With a $\mathrm{R}^{2}>99 \%$ the comparison of calculated PMV against thermal sensation votes is nearly identical to the measured PMV. However, the calculated PMV tends to slightly over predict cool sensation and under-predict warm sensation than the measured PMV, although both are higher than the actual thermal sensation. Nevertheless, PMV results derived from RayMan Pro with simulated $\mathrm{T}_{\mathrm{mrt}}$ data exhibit a close match to actual thermal sensation in Glasgow.

While the match between PMV and measured thermal sensation is very good, PMV itself is difficult to calculate given the importance of wind and $\mathrm{T}_{\mathrm{mrt}}$ at local scale. If wind data at street level cannot be accessed, the regression equation between $\mathrm{T}_{\mathrm{a}}$ and the thermal sensation can be used, too, showing a $\mathrm{R}^{2}$ of $86.2 \%$ (Figure 5 ). Since $\mathrm{T}_{\mathrm{a}}$ is easy to measure and widely included as part of many measurement campaigns, this close relationship is valuable to estimate thermal sensation during clear sky and moderate wind speed conditions, even though its performance is somewhat poorer than PMV.

The lower outlier at the $10^{\circ} \mathrm{C} \mathrm{T}_{\mathrm{a}}$ bin (Figure 5) is due to three very negative (-2 and -3 ) thermal sensation votes from the surveys in March 2011 which influence the mean thermal sensation. The second outlier at the $11^{\circ} \mathrm{C} \mathrm{T}_{\mathrm{a}}$ bin is strongly influenced by one thermal sensation vote of +2 which causes a relatively high mean thermal sensation. It should be noted that the thermal sensation of each individual is different and only the mean thermal sensation of a large group of people corresponds to the observed weather conditions. 


\section{2 'Optimal' comfort ranges}

The range of air temperature corresponding to satisfactory thermal environment (i.e. $-0.5<$ thermal sensation $<+0.5$ ) in Glasgow is $11.6-16.2^{\circ} \mathrm{C}$ (Table 5). This corresponds to a measured PMV range of +0.3 to +1.6 while calculated PMV ranges from -0.1 to +2.0 . This indicates that Glaswegian population considers what would otherwise be considered as 'cool' temperatures $\left(11.6-16.2^{\circ} \mathrm{C}\right)$ as 'comfortable' while slightly warmer conditions are considered as 'warmer than neutral.' Given the low annual average $\mathrm{T}_{\mathrm{a}}$ in Glasgow $\left(8.9^{\circ} \mathrm{C}\right)^{20}$, this provides indirect evidence to the theory of adaptive thermal comfort ${ }^{9}$ from a cold adaptation point of view. Nevertheless it is worth pointing out that only in five months of the year the outdoor temperature would fall within the $11.6-16.2^{\circ} \mathrm{C}$ range, indicating cold stress in the outdoors is clearly a significant problem. This is further accentuated by the PPD data which is discussed in Section 4.5 below.

(Table 5 here)

\subsection{Quality of predicted $T_{m r t}$ using RayMan Pro}

The comparison of measured $\mathrm{T}_{\mathrm{mrt}}$ against predicted $\mathrm{T}_{\mathrm{mrt}}$ shows a weak correlation $\left(\mathrm{R}^{2}=\right.$ $23.4 \%, \mathrm{p}<0.05)$ (see Figure 6). Differences between measured and calculated $\mathrm{T}_{\mathrm{mrt}}\left(\Delta_{\mathrm{Tmrt}}=\right.$ measured $\mathrm{T}_{\mathrm{mrt}}-$ calculated $\mathrm{T}_{\mathrm{mrt}}$ ) are large (ranging from -34.3 to +34.8 ). The mean measured $\mathrm{T}_{\mathrm{mrt}}\left(22.3^{\circ} \mathrm{C}\right)$ is lower than the mean calculated $\mathrm{T}_{\mathrm{mrt}}\left(25.2^{\circ} \mathrm{C}\right)$ suggesting that RayMan overestimates $\mathrm{T}_{\text {mrt }}$ data. Larger differences $\left(\Delta_{\mathrm{Tmrt}}>10^{\circ} \mathrm{C}\right)$ typically occurred between 10:00 11:00 a.m. local time. Given the low sun angles, this result is similar to Thorsson et al. ${ }^{28}$. However, two caveats are in order: global horizontal solar radiation was not measured at the thermal comfort survey sites but at a reference station located 0.5-1.1 km away (thus, there could be differences in the amount of cloud cover, which strongly influences $\mathrm{T}_{\mathrm{mrt}}$ ). 
Furthermore, given our focus on clear days, global radiation in the street canyons could have been overestimated due to reflected shortwave radiation.

(Figure 6 here)

Given the lack of comparable solar radiation data, it is difficult to justify the second caveat above. However, the effect of differences in cloud cover could be tested by considering a 25minute moving average $T_{\text {mrt }}$, which improved the coefficient of determination $\left(\mathrm{R}^{2}=35.9 \%\right)$.

\subsection{Comparison of calculated against measured PMV / PET}

Figure 7a shows a comparison of measured and calculated PMV. Raw data show a very high correlation $\left(\mathrm{R}^{2}=70 \%\right)$, although the correlation between measured and calculated $\mathrm{T}_{\mathrm{mrt}}$, which is one of the input variables, is weak. The same comparison was also conducted for Physiological Equivalent Temperature (PET) index (Figure 7b). These two indices were calculated using sky view photos and global horizontal solar radiation data as input.

\section{(Figure $7 \mathrm{a} / \mathrm{b}$ here)}

The coefficient of determination between PET calculated with measured $\mathrm{T}_{\mathrm{mrt}}$ vs. simulated $\mathrm{T}_{\mathrm{mrt}}\left(\mathrm{R}^{2}=66.7 \%\right)$ is weaker than the PMV correlation. However, correlation would be even better if individual clothing values are used.

The correlation between the thermal sensation votes and PET were conducted in previous studies ${ }^{17,18}$ where a good correlation was found $\left(\mathrm{R}^{2}=91 \%\right)$; however this was weaker than PMV. 


\section{$\underline{4.5 \text { Predicted Percentage of Dissatisfied - PPD }}$}

In order to estimate the amount of dissatisfied, PPD was calculated and the goodness of fit of the original PPD regression equation for the Glasgow area was tested. The predicted PPD, shown in Table 6, was calculated and compared to the actual percentage of dissatisfied (see Figure 8).

(Table 6 here)

(Figure 8 here)

The relationship between actual and computed PPD against the predicted thermal sensation votes for each of the $\mathrm{T}_{\mathrm{a}}$ / PMV bins show that the neutral zone $(\mathrm{TS}=0)$ for the theoretical PPD is below the minimum of the actual PPD. The thermal sensation vote for each $T_{a} /$ PMV bin shows greater variation (i.e. there are larger amount of dissatisfied) which is indicative of a greater diversity of thermal sensation in the outdoors. Based on this, the regression equation for the calculation of PPD (Equation 2) can empirically be adjusted to fit the actual percentage of dissatisfied, which generates the formula for adjusted PPD (PPD*) presented in Table 7.

(Table 7 here)

\section{Conclusions}

The regression equations of the actual thermal sensation votes against $T_{a}$, measured PMV and calculated PMV show excellent results. This indicates that PMV and $\mathrm{T}_{\mathrm{a}}$ data can be used for the prediction of outdoor thermal sensation, although clearly $\mathrm{T}_{\mathrm{a}}$ is a weaker, albeit easy-toobtain substitution. In the case of Glasgow's outdoors PMV data show even better relations than PET data ${ }^{17}$, which recommends the use of PMV for further studies. However, it should 
be kept in mind that we had excluded thermal sensation votes from persons not exposed to the outdoor conditions for a sufficiently long enough time as well as those not resident in the city. These factors may explain the better fit between thermal sensation and PMV, contrary to other studies in similar temperate climate cities ${ }^{14,15}$. Furthermore the measured PMV values were in a range similar to the actual sensation votes, which was not the case in the studies referred to above.

It should be further noted that these regression equations cannot be used in different climate regions since the acclimatization of the population needs to be considered. Furthermore, the use of $\mathrm{T}_{\mathrm{a}}$ as a predictor of the thermal sensation needs to be handled carefully. As our work has shown, rational thermal comfort indices clearly perform better while air temperature could provide an early indication of likely thermal comfort in the outdoors. In regions where $\mathrm{V}_{\text {wind }}$ is low, $\mathrm{T}_{\mathrm{mrt}}$ is a dominating factor and the correlation between $\mathrm{T}_{\mathrm{a}}$ and the thermal sensation becomes weaker ${ }^{29}$. Additionally, that fact that thermal comfort in the outdoors is further influenced by psychological adaptation ${ }^{13,14}$ too needs to be taken into account.

The 'optimal' PET comfort range for Glasgow $\left(9-18^{\circ} \mathrm{C}\right)^{17}$ is clearly below the suggested thermal comfort range from $18^{\circ} \mathrm{C}$ to $23^{\circ} \mathrm{C}^{21}$. The comparison of PET against thermal sensation votes in Glasgow shows a high correlation $\left(\mathrm{R}^{2}=91 \%\right)^{18}$ and thus is useful for the prediction of thermal comfort. Although PET is a commonly used index for the prediction of the thermal conditions of an outdoor environment ${ }^{21,28,29,30,31}$ our results suggest that both measured and calculated PMV are more consistent with the actual thermal sensation votes in Glasgow which recommends the use of PMV index for future investigations of the thermal sensation. However, it should be kept in mind that the above "comfort" zone is valid for outdoor clothing and activity. 
Given the low annual average temperature in the city, comfort ranges of $\mathrm{T}_{\mathrm{a}}$ indicate that heat stress and cold stress occur throughout the year whereas thermal discomfort due to cold is more frequent (annual mean temperature undershoots lower comfort threshold). However, the changing climate may lead to increased heat stress in the future. ${ }^{7}$

Additionally it is shown that the results for PMV attained by RayMan Pro using (1) measured input data (PMV $\left.\mathrm{V}_{\text {measured }}\right)$ and (2) fisheye photographs and site-specific global radiation data $\left(\mathrm{PMV}_{\text {calculated }}\right)$ both closely mimic actual thermal sensation. Thus, future thermal comfort studies can be conducted using RayMan Pro in combination with the adjusted regression equations for thermal comfort. Besides, thermal discomfort due to heat or cold can be assessed using the suggested optimal thermal comfort range for PMV / $\mathrm{T}_{\mathrm{a}}$ (Table 5).

Several studies mention that $\mathrm{T}_{\text {mrt }}$ is the climate variable which influences the human energy balance the most ${ }^{16,29}$ and thus shows the strongest correlation with thermal sensation votes. In contrast to those findings, our results show a better fit for $\mathrm{T}_{\mathrm{a}}$ data. As Höppe ${ }^{11}$ points out, $T_{a}$ becomes more dominant in windy conditions as it is the case in Glasgow, because $T_{a}$ bestrides the convective heat exchange. This explains the better fit of thermal sensation votes against $T_{a}$ data compared to $T_{m r t}$ data and enables planners and urban designers to estimate the thermal sensation by means of easy-to-access $T_{a}$ data. However, as other studies ${ }^{16,29}$ suggest, in different climate conditions, this close relationship between $\mathrm{T}_{\mathrm{a}}$ and thermal sensation votes might not be valid and $\mathrm{T}_{\text {mrt }}$ dominates the thermal sensation. Furthermore, it is important to keep in mind that $\mathrm{T}_{\mathrm{a}}$ itself cannot be directly influenced by urban design. However, given its widespread use and greater popular awareness, $\mathrm{T}_{\mathrm{a}}$ is a useful medium in which to express the likely thermal comfort implications of design options.

PPD results for Glasgow indicates the presence of a large amount of dissatisfied for a predicted thermal sensation of " 0 " compared to computed PPD (Fig. 7). This demonstrates 
the greater diversity of the thermal sensation of the Glaswegian population and the adjusted PPD (PPD*) should be considered for further studies. Such works could explore outdoor design strategies that could decrease the percentage of dissatisfied in Glasgow to increase the comfort conditions in this cold temperate climate.

For further studies which examine the thermal comfort in urban areas in windy temperate climate conditions, the close link between the thermal sensation and $\mathrm{T}_{\mathrm{a}}$, will especially be useful, since it enables planners and architects to assess thermal comfort data by easy-toaccess $T_{a}$ data. Therefore, future studies that require a lot of measurement sites, e.g. studies which aim at finding a link between urban morphology and thermal comfort, can be carried out easily.

\section{Acknowledgements}

The Brazilian funding agency Conselho Nacional de Desenvolvimento Científico e Tecnológico - CNPq, through the program Science without Borders, and the School of Engineering and Built Environment at Glasgow Caledonian University.

Erasmus - work placement exchange between Albert-Ludwigs-Universität Freiburg, Germany and Glasgow Caledonian University, Scotland. 


\section{Appendix:}

\section{Comfort questionnaire (based on ISO 10551)}

Date:

Time:

Part 1: background and personal information

Gender (circle it): $\quad$ Male $\quad$ Female

Age:

Weight:

Height:

Time of residency (Glasgow or UK, circle it):

less than 6 months

more than 6 months

Time spent outdoors (minutes):

Part 2: current clothing garments (clothing ensembles as in ISO 9920, refer to Table Annex A)

Part 3: How do you feel at this precise moment?
$(-3)$ cold
$(-2)$ cool
(-1) slightly cool
(0) neutral
$(+1)$ slightly warm
$(+2)$ warm
$(+3)$ hot

Part 4: Please state how you would prefer to be now:
$(+3)$ much warmer
$(+2)$ warmer
$(+1)$ a little warmer
(0) neither warmer nor cooler
$(-1)$ a little cooler
$(-2)$ cooler
(-3) much cooler 


\section{References}

${ }^{1}$ Ebi K, Burton I, McGregor G R. 2009: Biometeorology for adaptation to climate variability and change, Dortrecht: Springer

${ }^{2}$ VDI, 1998: VDI 3787. Methoden zur human-biometeorologischen Bewertung von Klima und Lufthygiene für die Stadt- und Regionalplanung. Teil I: Klima. Verein deutscher Ingenieure, Düsseldorf

${ }^{3}$ Kovats RS, Hajat S, 2008: Heat Stress and Public Health: A Critical Review. Annu Rev Publ Health, $29,41-55$

${ }^{4}$ Vanos, J.K.; Warland, J.S.; Gillespie, T.J.; Kenny, N.A.; 2010: Review of the physiology of human thermal comfort while exercising in urban landscapes and implications for bioclimatic design. Int J Biometeorol 54, 319-334

${ }^{5}$ Hajat S, Kosatky T. 2010: Heat-related mortality: a review and exploration of heterogeneity, $J$ Epidemiol Commun H, 64, 753-760

${ }^{6}$ Holst, J.; Mayer, H.; 2011: Impacts of street design parameters on human-biometeorological variables. Meteorol Z, 20, 541-552

${ }^{7}$ Gul M, Jenkins DP, Patidar S, Banfill PFG, Menzies G, Gibson G. 2012: Tailoring a future overheating risk tool for existing building design practice in domestic and non-domestic sectors, Build Serv Eng Res T, 33, 105-117

${ }^{8}$ Mavrogianni A, Davies M, Batty M, Belcher SE, Bohnenstengel SI, Carruthers D, Chalabi Z, Croxford B, Demanuele C, Evans S, Giridharan R, Hacker JN, Hamilton I, Hogg C, Hunt J, Kolokotroni M, Martin C, Milner J, Rajapaksha I, Ridley I, Steadman JP, Stocker J, Wilkinson P, Ye Z. 2011: The comfort, energy and health implications of London's urban heat island, Build Serv Eng Res T, 32, 35-52

${ }^{9}$ Humphreys MA, Rijal HB, Nicol JF. 2013: Updating the adaptive relation between climate and comfort indoors; new insights and an extended database, Build Environ, 63, 40-55

${ }^{10}$ ISO 7730, 2005: Moderate thermal environments - determination of the PMV and PPD indices and specification of the conditions for thermal comfort, Geneva: International Standard, Third Edition

${ }^{11}$ Höppe P. 1999: The physiological equivalent temperature - a universal index for the biometeorological assessment of the thermal environment, Int J Biometeorol, 43, 71-75

${ }^{12}$ Matzarakis A, Rutz F, Mayer H. 2006: Modelling the thermal bioclimate in urban areas with the RayMan Model. PLEA2006 - The $23^{\text {rd }}$ Conference on Passive and Low Energy Architecture, Geneva, Switzerland

${ }^{13}$ Eliasson I, Knez I, Westerberg U, Thorsson S, Lindberg F. 2007: Climate and behaviour in a Nordic city, Landscape Urban Plan, 82, 1-2, 72-84

${ }^{14}$ Nikolopoulou M, Baker N, Steemers K. 2001. Thermal comfort in outdoor urban spaces: understanding the human parameter, Sol Energy, 70, 3, 227-235

${ }^{15}$ Thorsson S, Lindqvist M, Lindqvist S. 2004: Thermal bioclimatic conditions and patterns of behaviour in an urban park in Göteborg, Sweden, Int J Biometeorol, 48, 3, 149-156

${ }^{16}$ Lindberg F, Holmer B, Thorsson S, 2008: SOLWEIG 1.0 - Modelling spatial variations of 3D radiant fluxes and mean radiant temperature in complex urban settings. Int J Biometeorol, 52, 697-713

${ }^{17}$ Krüger E, Drach P, Emmanuel R, Corbella O. 2013: Assessment of daytime outdoor comfort levels in and outside the urban area of Glasgow, UK. Int J Biometeorol, 57, 4, 521-533 
${ }^{18}$ Krüger E, Drach P, Emmanuel R, Corbella O. 2013: Urban heat island and differences in outdoor comfort levels in Glasgow, UK. Theor Appl Climatol, 112, 127-141

${ }^{19}$ ISO 7726, 1998: Ergonomics of the thermal environment - Instruments for measuring physical quantities. Geneva: International Standard

${ }^{20} \mathrm{UK}$ Met Office. Monthly and annual average climate data at $5 \mathrm{~km}$ resolution. http://www.metoffice.gov.uk/climate/uk/stationdata/. Accessed 16 July 2014

${ }^{21}$ Matzarakis A, Mayer H, Iziomon M G, 1999: Applications of a universal thermal index: physiological equivalent temperature, Int J Biometeorol, 43, 76-84

${ }^{22}$ Nikolopoulou M, Baker N, Steemers K. 1999: Improvements to the globe thermometer for outdoor use. Architectural Science Review, 42, 27-34

${ }^{23}$ ISO 10551, 1995: Ergonomics of the thermal environment-assessment of the influence of the thermal environment using subjective judgement scales. Geneva: International Standard

${ }^{24}$ ANSI/ASHRAE, 2004: Thermal Environmental Conditions for Human Occupancy (ANSI Approved). American Society of Heating, Refrigerating, and Air-Conditioning Engineers. Standard 55-2004

${ }^{25}$ Höppe, P. 2002: Different aspects of assessing indoor and outdoor thermal comfort. Energ Buildings, 34, 661-665

${ }^{26}$ Matzarakis A, Rutz F, Mayer H. 2010: Modelling radiation fluxes in simple and complex environments: basics of the RayMan model, Int J Biometeorol, 54, 131-139

${ }^{27}$ The R Project for Statistical Computing, 2013: R was developed at Bell Laboratories (formerly AT\&T, now Lucent Technologies) by John Chambers and colleagues. Available at: http://www.rproject.org/

${ }^{28}$ Thorsson S, Lindberg F, Eliasson I, Holmer B, 2007: Different methods for estimating the mean radiant temperature in an outdoor urban setting, Int J Climatol, 27, 1983-1993

${ }^{29}$ Mayer H, Holst J, Dostal P, Imbery F, Schindler D, 2008: Human thermal comfort in summer within an urban street canyon in Central Europe, Meteorol Z, 17, 241-250

${ }^{30}$ Svensson MK, Thorsson S, Lindqvist S, 2003: A geographical information system model for creating bioclimatic maps - examples from a high, mid-latitude city, Int J Biometeorol, 47, $102-$ 112

${ }^{31}$ Ali-Toudert F, Mayer H, 2006: Numerical study on the effects of aspect ratio and orientation of an urban street canyon on outdoor thermal comfort in hot and dry climate, Build Environ, 41, 94-108

${ }^{32}$ Johansson E, Thorsson S, Emmanuel R, Krüger E. 2014. Instruments and methods in outdoor thermal comfort studies - The need for standardization, Urban Climate, DOI: http://dx.doi.org/10.1016/j.uclim.2013.12.002 
Table 1 Equipment characteristics

\begin{tabular}{llll}
\hline Sensor & Resolution & $\begin{array}{l}\text { Measurement } \\
\text { range }\end{array}$ & Accuracy \\
\hline Air temperature & $\begin{array}{l}0.1^{\circ} \mathrm{C} \text { or } 1{ }^{\circ} \mathrm{C} \\
\text { (user-selectable) }\end{array}$ & $-25^{\circ}$ to $+85^{\circ} \mathrm{C}$ & $\begin{array}{l} \pm 0.5^{\circ} \mathrm{C} \text { above } \\
20^{\circ} \mathrm{F}\left(-7{ }^{\circ} \mathrm{C}\right)\end{array}$ \\
\hline Relative Humidity & $1 \%$ & 1 to $100 \%$ & $\begin{array}{l} \pm 3 \%(0-90 \%) . \\
\pm 4 \%(90-100 \\
\%)\end{array}$ \\
& & & $\pm 1 \mathrm{~m} / \mathrm{s}$ \\
\hline Air velocity & $0.4 \mathrm{~m} / \mathrm{s}$ & 1 to $80 \mathrm{~m} / \mathrm{s}$ & $\pm 3^{\circ}$ \\
\hline Wind direction & $22.5^{\circ}$ & $0-360^{\circ}$ & 0 to $1800 \mathrm{~W} / \mathrm{m}^{2}$ \\
\hline Solar radiation & $1 \mathrm{~W} / \mathrm{m}^{2}$ & & \\
\hline
\end{tabular}


Table 2 Characteristics of the thermal sensation measurement sites

\begin{tabular}{|c|c|c|c|}
\hline $\begin{array}{c}\text { Code, location } \\
\text { and SVF }\end{array}$ & Fisheye photo & $\begin{array}{c}\text { Code, location } \\
\text { and SVF } \\
\end{array}$ & Fisheye photo \\
\hline $\begin{array}{c}\text { Point } 1 \\
55^{\circ} 51^{\prime} 50.06^{\prime \prime} \mathrm{N} \\
4^{\circ} 15^{\prime} 10.17^{\prime \prime} \mathrm{W}\end{array}$ & & $\begin{array}{c}\text { Point } 2 \\
55^{\circ} 51^{\prime} 33.48^{\prime \prime} \mathrm{N} \\
4^{\circ} 15^{\prime} 16.40^{\prime \prime} \mathrm{W}\end{array}$ & \\
\hline $\mathrm{SVF}=0.287$ & & $\mathrm{SVF}=0.278$ & \\
\hline $\begin{array}{c}\text { Point } 3 \\
55^{\circ} 51^{\prime} 27.93^{\prime \prime} \mathrm{N} \\
4^{\circ} 15^{\prime} 4.74^{\prime \prime} \mathrm{W}\end{array}$ & & $\begin{array}{c}\text { Point } 4 \\
55^{\circ} 51^{\prime} 43.14^{\prime \prime} \mathrm{N} \\
4^{\circ} 15^{\prime} 13.14^{\prime \prime} \mathrm{W}\end{array}$ & \\
\hline $\mathrm{SVF}=0.337$ & & $\mathrm{SVF}=0.309$ & \\
\hline $\begin{array}{c}\text { Point } 5 \\
55^{\circ} 51^{\prime} 52.66^{\prime \prime} \mathrm{N} \\
4^{\circ} 15^{\prime} 23.11^{\prime \prime} \mathrm{W}\end{array}$ & & $\begin{array}{c}\text { Point } 6 \\
55^{\circ} 51^{\prime} 39.65^{\prime \prime} \mathrm{N} \\
4^{\circ} 15^{\prime} 14.02^{\prime \prime} \mathrm{W}\end{array}$ & \\
\hline $\mathrm{SVF}=0.313$ & & & \\
\hline
\end{tabular}


Table 3 Bins used for computing the regression equations

\begin{tabular}{lllll}
\hline \multirow{4}{*}{} & $\begin{array}{l}\text { Bin } \\
\text { width }\end{array}$ & $\begin{array}{l}\text { Number } \\
\text { of bins }\end{array}$ & $\begin{array}{l}\text { Minimum } \\
\text { bin }\end{array}$ & $\begin{array}{l}\text { Maximum } \\
\text { bin }\end{array}$ \\
\cline { 2 - 5 } $\mathrm{T}_{\mathrm{a}}$ & $1\left({ }^{\circ} \mathrm{C}\right)$ & 14 & $8\left({ }^{\circ} \mathrm{C}\right)$ & $21\left({ }^{\circ} \mathrm{C}\right)$ \\
$\mathrm{T}_{\text {mrt }}$ measured & $2\left({ }^{\circ} \mathrm{C}\right)$ & 25 & $10\left({ }^{\circ} \mathrm{C}\right)$ & $50\left({ }^{\circ} \mathrm{C}\right)$ \\
$\mathrm{T}_{\text {mrt }}$ calculated & $2\left({ }^{\circ} \mathrm{C}\right)$ & 27 & $8\left({ }^{\circ} \mathrm{C}\right)$ & $52\left({ }^{\circ} \mathrm{C}\right)$ \\
PMV measured & 1 & 7 & -3 & +3 \\
PMV calculated & 1 & 8 & -3 & +4 \\
\hline
\end{tabular}


Table 4 Performance of calculated and measured indices against actual thermal sensation

\begin{tabular}{lcccccc}
\hline & \multicolumn{3}{c}{ Raw Data } & \multicolumn{3}{c}{ Binned data } \\
\cline { 2 - 7 } & $\mathrm{R}^{2}$ & Pearsons $\mathrm{r}$ & $\mathrm{p}$-value & $\mathrm{R}^{2}$ & Pearsons $\mathrm{r}$ & $\mathrm{p}$-value \\
\hline $\mathrm{TS} \sim \mathrm{T}_{\mathrm{a}}$ & $20 \%$ & 0.45 & $<<0.05$ & $86.2 \%$ & 0.93 & $<<0.05$ \\
$\mathrm{TS} \sim \mathrm{T}_{\text {mrt }}$ measured & $9.5 \%$ & 0.31 & $<<0.05$ & $59.8 \%$ & 0.77 & $<<0.05$ \\
$\mathrm{TS} \sim \mathrm{T}_{\text {mrt }}$ calculated & $5.6 \%$ & 0.24 & $<<0.05$ & $68.9 \%$ & 0.83 & $<<0.05$ \\
$\mathrm{TS} \sim \mathrm{PMV}_{\text {measured }}$ & $18.0 \%$ & 0.42 & $<<0.05$ & $99.3 \%$ & 0.996 & $<<0.05$ \\
$\mathrm{TS} \sim \mathrm{PMV}_{\text {calculated }}$ & $10.9 \%$ & 0.33 & $<<0.05$ & $99.4 \%$ & 0.997 & $<<0.05$ \\
\hline
\end{tabular}


Table 5 'Optimal' thermal comfort $(-0.5<$ thermal sensation $<+0.5)$ ranges

\begin{tabular}{lrr}
\hline & $\begin{array}{r}\text { Lower threshold } \\
(\mathrm{TS}=-0.5)\end{array}$ & \multicolumn{2}{c}{$\begin{array}{c}\text { Upper threshold } \\
(\mathrm{TS}=+0.5)\end{array}$} \\
\hline Measured PMV & +0.3 & +1.6 \\
Calculated PMV (RayMan) & -0.1 & +2.0 \\
Measured $\mathrm{T}_{\mathrm{mrt}}\left({ }^{\circ} \mathrm{C}\right)$ & +10.3 & +30.9 \\
Calculated $\mathrm{T}_{\mathrm{mrt}}\left({ }^{\circ} \mathrm{C}\right)$ & +7.6 & +33.2 \\
$\mathrm{~T}_{\mathrm{a}}\left({ }^{\circ} \mathrm{C}\right)$ & +11.6 & +16.2 \\
\hline
\end{tabular}


Table 6 Actual and adjusted PPD for Glasgow and the corresponding PMV / $\mathrm{T}_{\mathrm{a}}$ bins

\begin{tabular}{|c|c|c|c|}
\hline PMV bin & $\begin{array}{c}\text { Actual PPD } \\
(\%)\end{array}$ & $\begin{array}{c}\text { PPD* (adjusted) } \\
\text { (\%) }\end{array}$ & Thermal sensation (TS) \\
\hline Measured PMV & & & $\mathrm{TS}=-0.76176+0.79569 * \mathrm{PMV}$ \\
\hline-3 & NA & 99.9 & -3.1 \\
\hline-2 & NA & 94.1 & -2.4 \\
\hline-1 & NA & 59.1 & -1.6 \\
\hline \pm 0 & 31.4 & 33.9 & -0.8 \\
\hline+1 & 30.9 & 30.6 & 0.0 \\
\hline+2 & 37.1 & 34.9 & +0.8 \\
\hline+3 & 62.5 & 62.6 & +1.6 \\
\hline Calculated PMV $^{\dagger}$ & & & $\mathrm{TS}=-0.45433+0.48456 * \mathrm{PMV}$ \\
\hline-3 & NA & 69.3 & -1.9 \\
\hline-2 & NA & 59.8 & -1.4 \\
\hline-1 & NA & 45.0 & -0.9 \\
\hline \pm 0 & 20.0 & 30.5 & -0.5 \\
\hline+1 & 32.8 & 24.9 & 0 \\
\hline+2 & 30.4 & 32.0 & +0.5 \\
\hline+3 & 52.5 & 47.0 & +1.0 \\
\hline $\mathrm{T}_{\mathrm{a}}\left({ }^{0} \mathrm{C}\right)$ & & & $\mathrm{TS}=-2.92597+0.21188 * \mathrm{~T}_{\mathrm{a}}$ \\
\hline 8 & 47.4 & 49.5 & -1.2 \\
\hline 9 & 35.7 & 35.4 & -1.0 \\
\hline 10 & 50.0 & 31.1 & -0.8 \\
\hline 11 & 16.7 & 29.5 & -0.6 \\
\hline 12 & 35.5 & 30.1 & -0.4 \\
\hline 13 & 31.8 & 31.1 & -0.2 \\
\hline 14 & 31.7 & 31.4 & 0 \\
\hline 15 & 29.9 & 30.8 & +0.3 \\
\hline 16 & 29.0 & 29.8 & +0.5 \\
\hline 17 & 21.1 & 29.8 & +0.7 \\
\hline 18 & 39.4 & 32.9 & +0.9 \\
\hline 19 & 38.1 & 41.3 & +1.1 \\
\hline 20 & 47.6 & 55.5 & +1.3 \\
\hline 21 & 80.0 & 72.7 & +1.5 \\
\hline
\end{tabular}

Notes

${ }^{\dagger}-$ Equations only valid in the range from TS $=\sim-2$ to $\sim+2$ (which corresponds to the range of thermal sensation calculations) 
Table 7 Adjusted regression equations for PPD

\begin{tabular}{llll}
\hline $\begin{array}{l}\text { Original PPD } \\
\text { equation (ISO } \\
7730)^{10}\end{array}$ & $\begin{array}{l}\mathrm{PPD}=100-95 * \exp \left(-0.03353 * \mathrm{PMV}^{4}-\right. \\
\left.0.2179 * \mathrm{PMV}^{2}\right)\end{array}$ & Equation 2 & - \\
\hline Best-fit for $\mathrm{T}_{\mathrm{a}}$ & $\mathrm{PPD}^{*}=100-69 * \exp \left(-0.2411 * \mathrm{TS}^{4}+\right.$ & Equation 3 & $\mathrm{R}^{2}=75.7 \%$ \\
& $\left.0.1636 * \mathrm{TS}^{2}\right)$ & & \\
\hline $\begin{array}{l}\text { Best fit for } \\
\text { measured PMV }\end{array}$ & $\mathrm{PPD}^{*}=100-69 * \exp \left(-0.0727 * \mathrm{TS}^{4}-\right.$ & Equation 4 & $\mathrm{R}^{2}=98.7 \%$ \\
\hline $\begin{array}{l}\text { Best-fit for } \\
\text { calculated PMV }\end{array}$ & $\left.0.0414 * \mathrm{TS}^{2}\right)$ & & \\
\hline
\end{tabular}




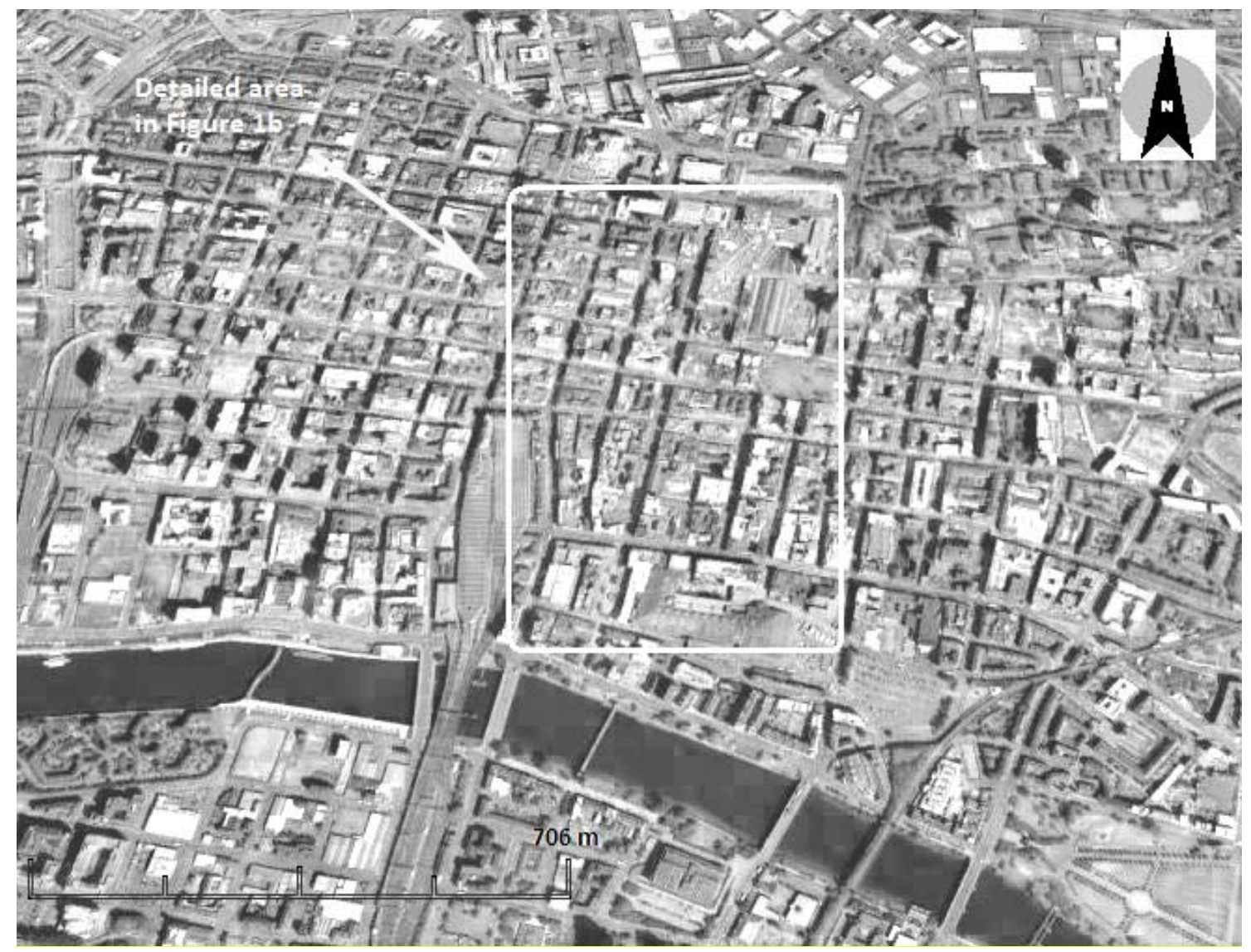

Figure 1a Glasgow city centre map

Source: Google Earth 


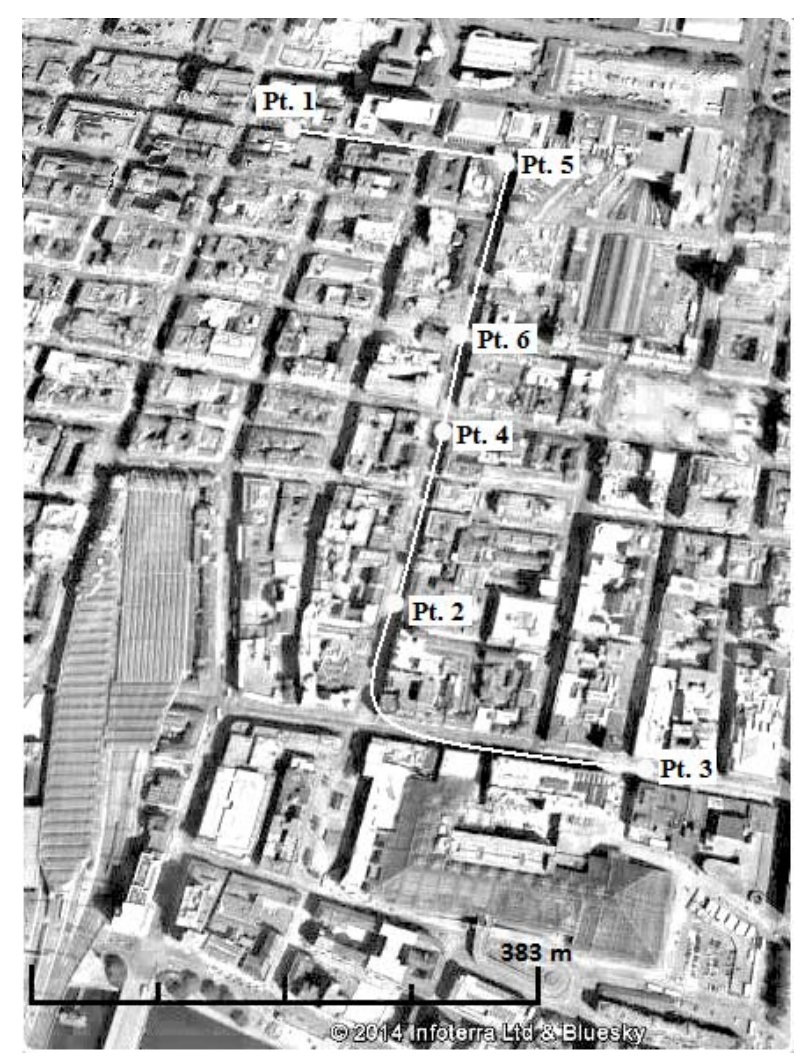

Figure 1b Thermal comfort survey sites

Source: Google Earth 

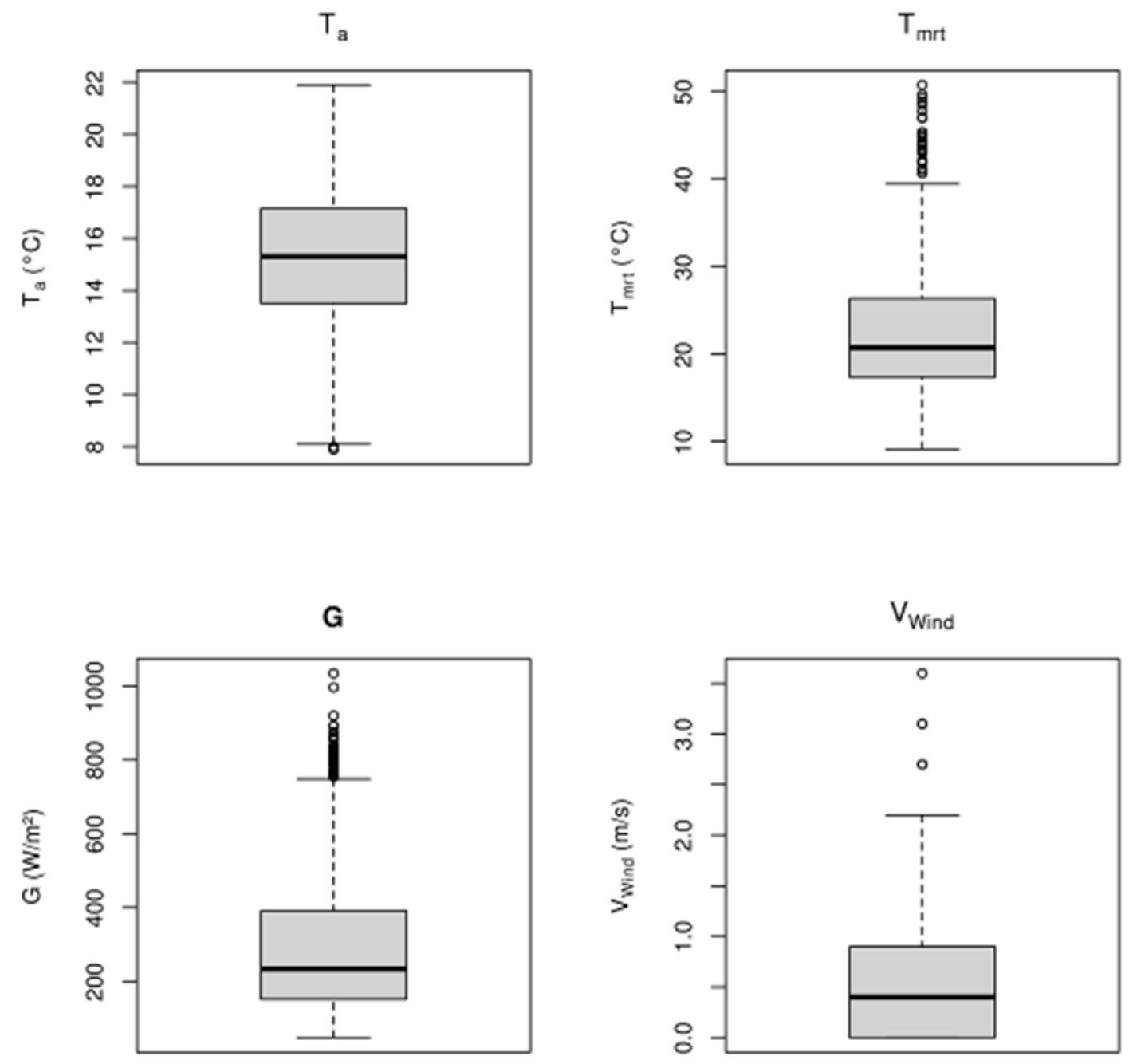

Figure 2 Weather conditions during the measurement period

\section{Note:}

Boxplots of air temperature ( $\mathrm{T}_{\mathrm{a}}$ ) (top left), mean radiant temperature ( $\left.\mathrm{T}_{\mathrm{mrt}}\right)$ (top right), global horizontal solar radiation $(\mathrm{G})$ (bottom left) and wind velocity $\left(\mathrm{V}_{\text {wind }}\right)$ (bottom right) for the measurement campaigns between March and July 2011 in the Glasgow city centre. The solid black line is the median and the dashed line shows the mean; the lower and upper edge of the box are first and third quartile; the error bars show extreme values which are within 1.5 times the Inter quartile range (IQR); the dots show extreme values beyond 1.5 IQR. 

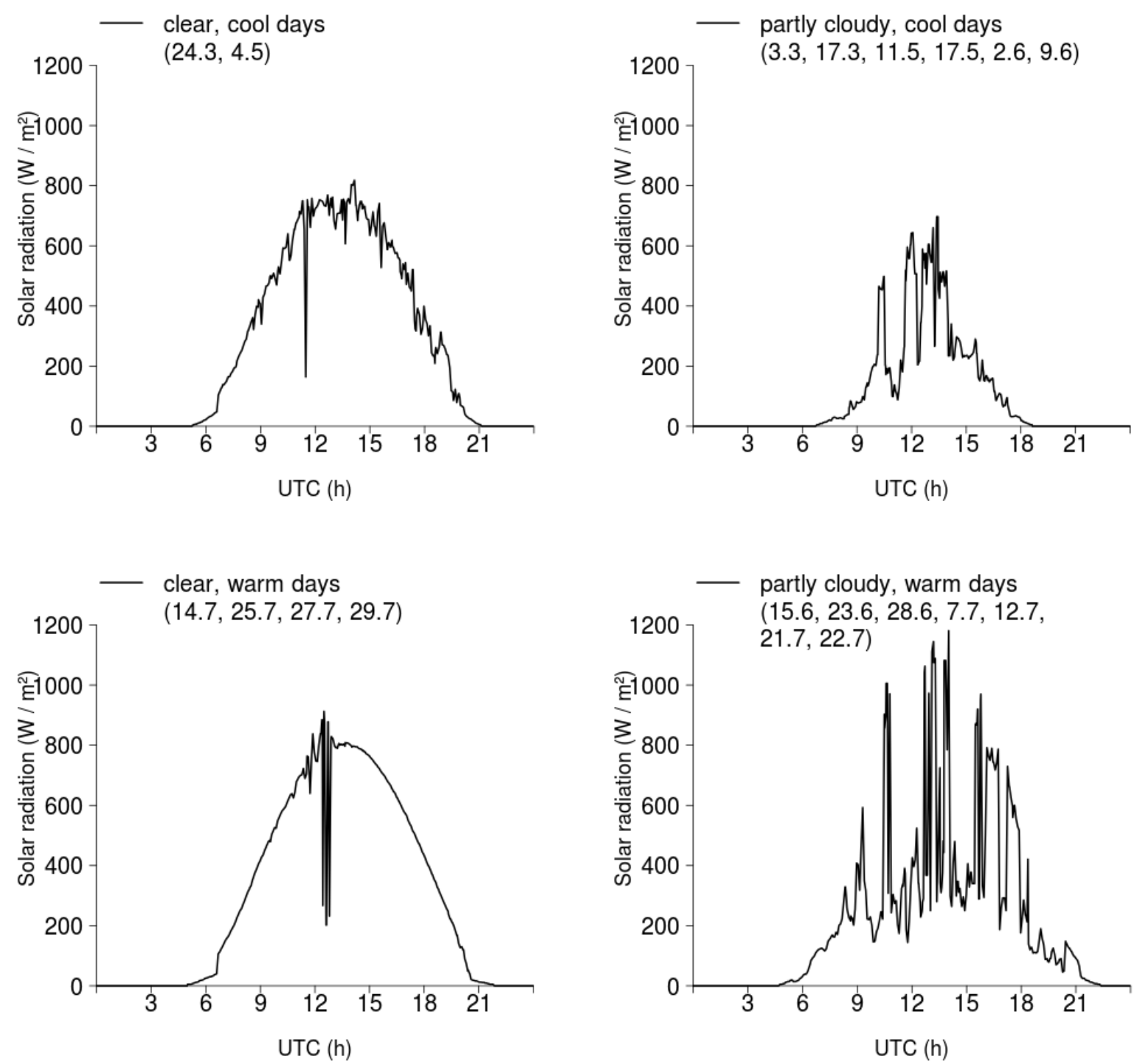

Figure 3 Typical solar radiation profiles on the survey days

Note:

Figures in parenthesis indicate the thermal comfort survey dates in date.month format 


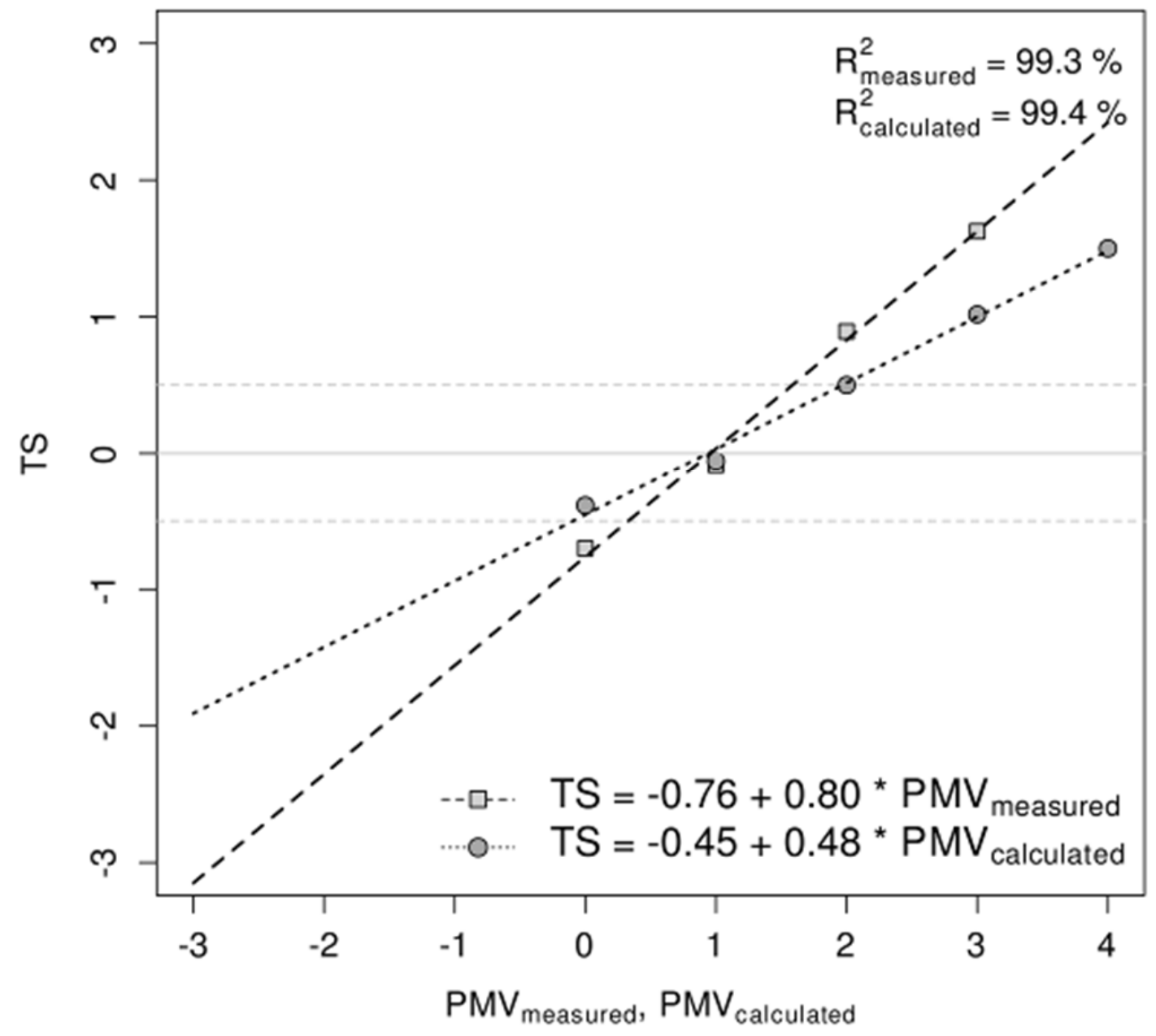

Figure 4 Mean thermal sensation votes against calculated (RayMan) and measured PMV 


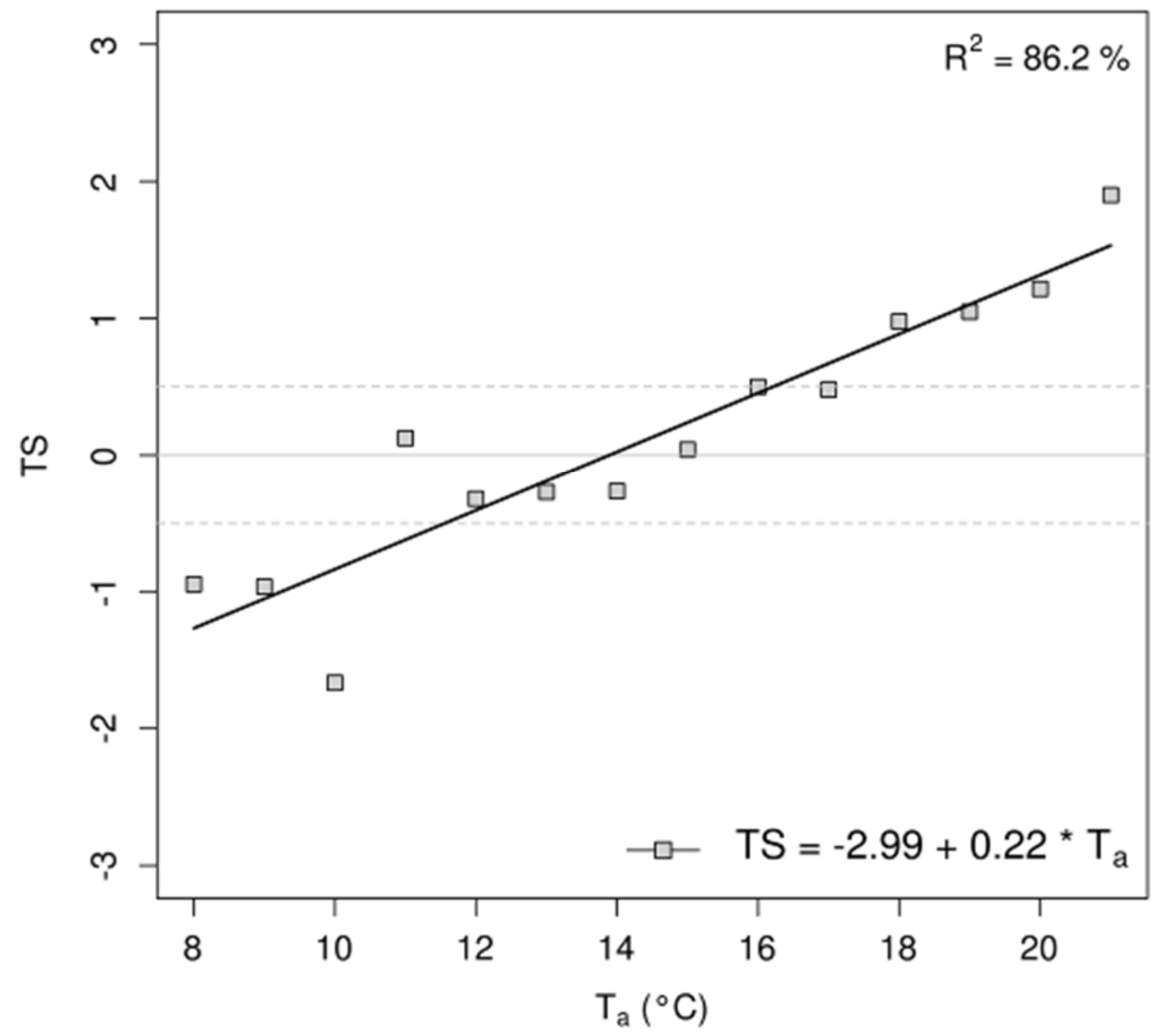

Figure 5 Mean thermal sensation votes and binned $\mathrm{T}_{\mathrm{a}}$ classes for Glasgow 


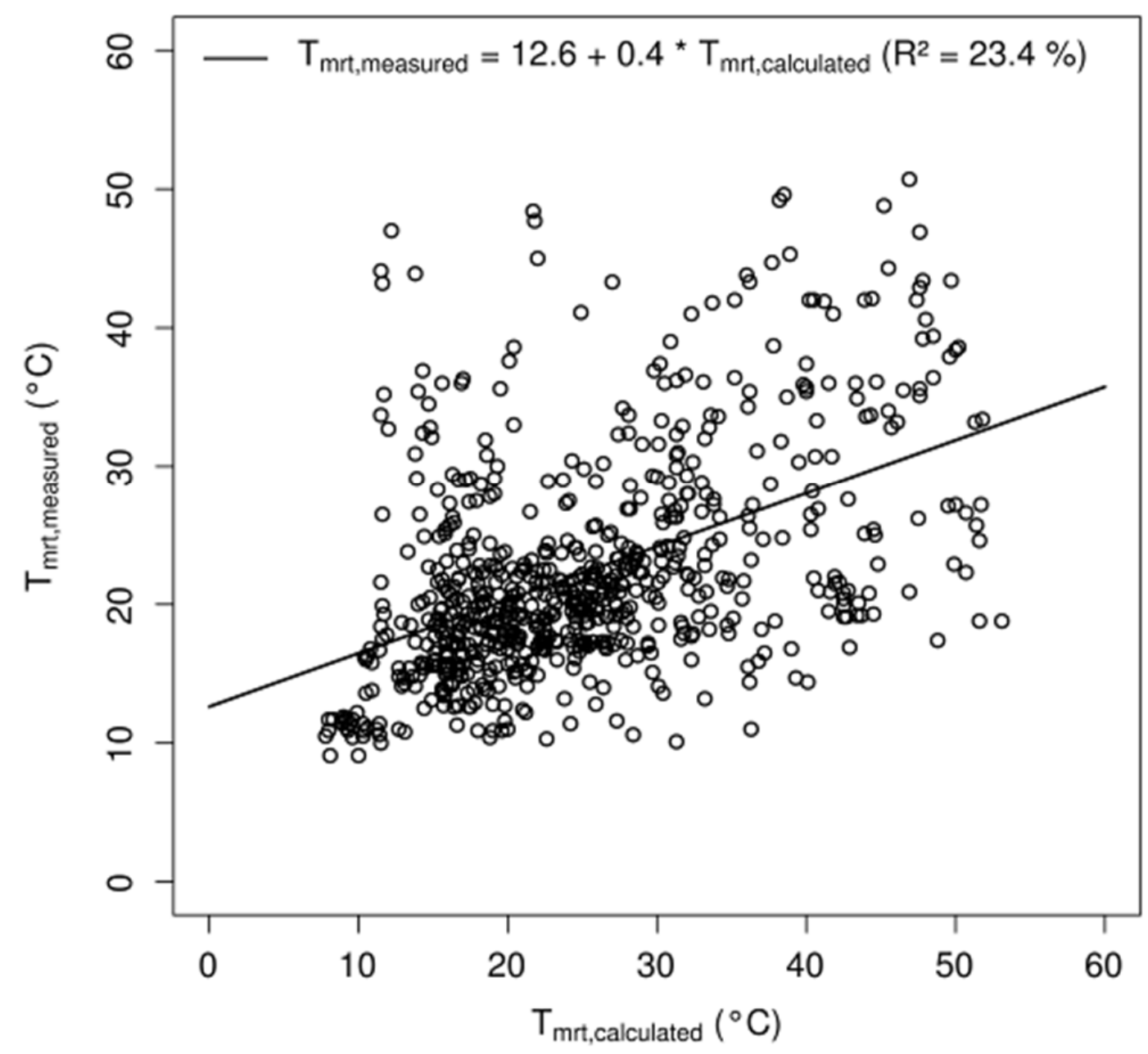

Figure 6 Measured $T_{m r t}$ data and predicted $T_{m r t}$ data using RayMan for Glasgow 

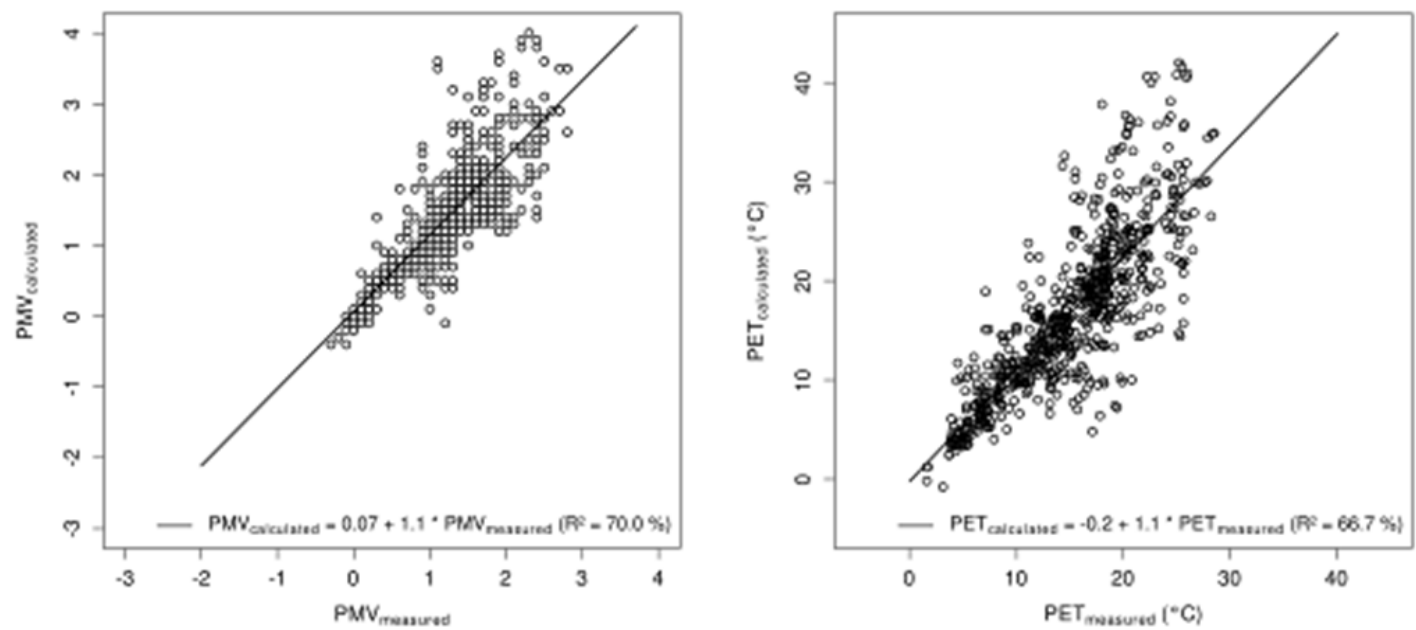

Figure 7 Correlation between measured and calculated (a) PMV and (b) PET for Glasgow 

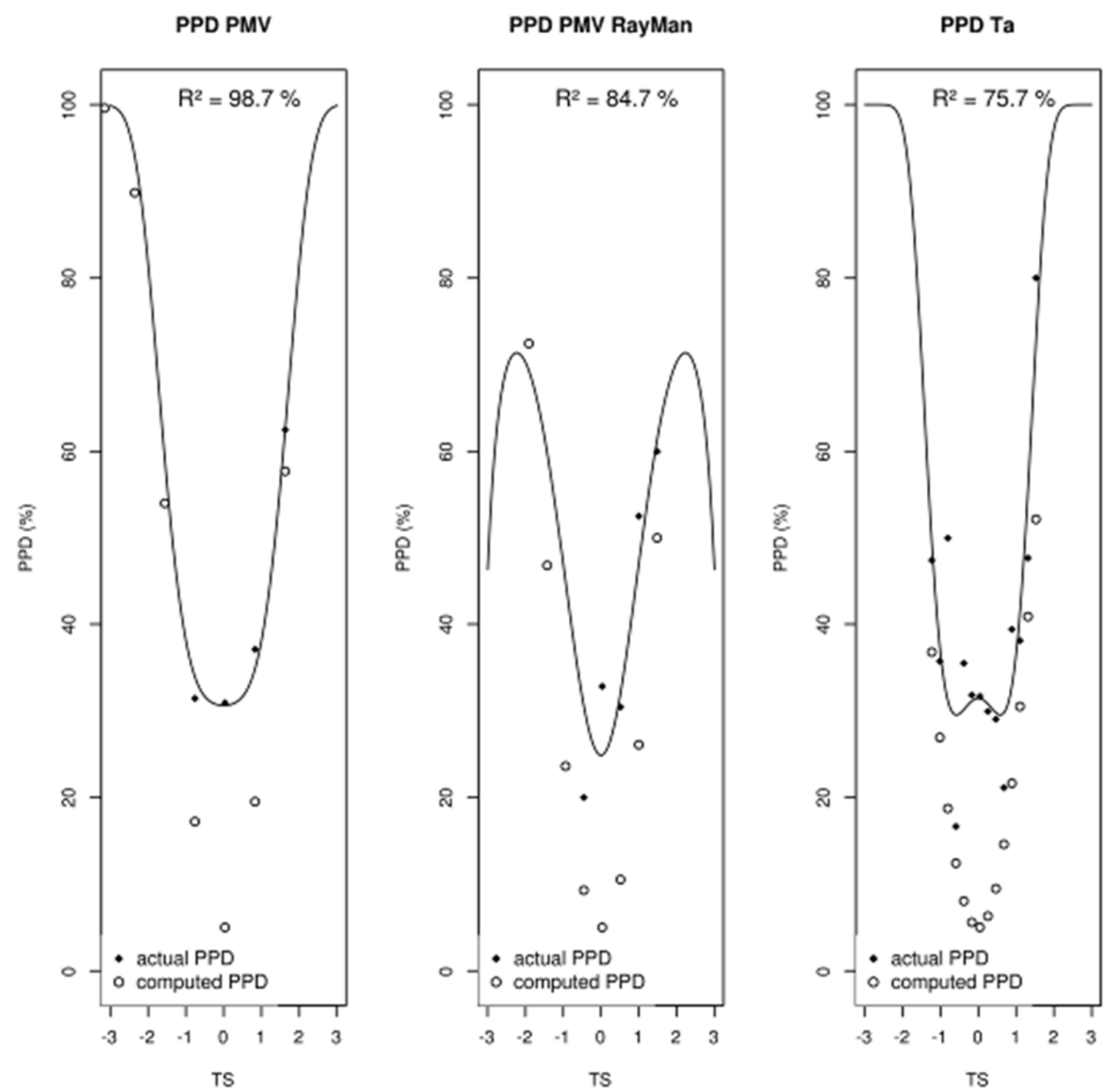

Figure 8 Actual and computed PPD for Glasgow. The parabola shows the adjusted PPD* regression parabola (equations are provided in table PPD*). 